\title{
THE ANALYSIS OF UNDERGRADUATES' ENTREPRENEURIAL TREND
}

\section{Dr. Le Nguyen Doan Khoi* \\ Assoc. Prof., Department Of Scientific Research Affairs,can Tho University ${ }^{*}$ Corresponding Author}

ABSTRACT This paper focuses on the extent to which undergraduate students at universities might wish to create their own companies on graduation. The statistical procedures adopted in the processing of the data collected from a sample of 450 undergraduates in order to better understand student attitudes regarding their paths from university education into the labour market - with particular regard to the possibility of their establishing their own enterprise. Gender, risk, factors related to profession/employment choice and academic training were found to significantly affect students' interest in and motivation for starting their own business.

KEYWORDS : Entrepreneurship, Entrepreneurial Trend, Start-ups Business, Undergraduates

\section{INTRODUCTION}

In recent years, the rapid changes unleashed by a new phase of globalisation, combined with a deteriorating economic conjuncture has shrunk recruitment and/or significantly altered employment conditions in many of the traditional types of employment that, in the past, absorbed most university students. Today, graduating students are more likely than before to see the possibility of establishing their own enterprises as a positive rather than residual career option (Kolvereid\& Moen, 1997). However, both the extent of the propensity for students to do so and the opportunities for them to accumulate the necessary attributes and competencies would appear to be highly variable between countries and regions, as well as between courses of study.

Though there appears to be widespread agreement concerning the main factors at work when employed professionals opt to establish their own firms, it would be unwise and inappropriate to uncritically assume that these factors play exactly the same role when the research focuses on recently-graduated university students. The research on which this paper reports was undertaken with a view to contributing to our understanding of the determinants of student trend to start their own businesses on graduation by focusing in particular on the analysis of those personal attributes and competencies that exert greatest influence on such intentions - without, of course, denying the importance of contextual/environmental factors in moulding perceptions and consequent decisions.

\section{LITERATURE REVIEW}

Various studies, both in the USA, (e.g. Kourilsky\&Walstad, 1998; Lüthje\& Franke, 2003; Van Auken et al., 2006) and in Europe (e.g. Kolvereid\& Moen, 1997; Gürul\&Atson, 2006) have provided clear evidence of a general growth in people's propensity to create their own enterprises. A number of recent studies (e.g. Lena \& Wong, 2003; Franke \&Luthje, 2004; Teixeira, 2007; Rodrigues et al, 2008) have attempted to gain a better understanding of precisely which variables may contribute most significantly to graduate business start-ups.

In much of the literature on entrepreneurial activities, there has been consistent interest in identifying the factors that lead an individual to become an entrepreneur (Kourilsky, 1980; Koh, 1996; Martínezet al., 2007). According to several authors (e.g. Carlandet al., 1984; Hatten \&Ruhland, 1995), the behavioural characteristics most commonly found in entrepreneurs include their propensity for innovation and their use of strategic management practices in their entrepreneurial initiatives. Additionally, the belief that entrepreneurs have distinctive psychological characteristics has a long tradition in entrepreneurship research (Gartner, 1988). Numerous studies have focused on personality traits that may be in some way connected to entrepreneurial behaviour through their influence over either the constitution of future entrepreneurial intentions and/or the reinforcement of established ones (Kennedy et al., 2003; Brice, 2004; LiñónAlcalde\& Rodríguez-Cohard, 2004; Barahona\&Escudero, 2005; Asiớn, 2005; Li, 2006).

Individual personal/demographic characteristics such as those relating to gender, age, educational status and regional origin, can be used to describe existing or potential entrepreneurs (as opposed to purely psychological traits): however, most of these variables appear to have little or no influence on an person's predisposition for entrepreneurship, nor can they be used as predictors of such a career or lifestyle choice (Robinson et al., 1991; Hatten \&Ruhland, 1995).

The second method of assessing entrepreneurial tendencies is to examine personality traits such as achievement motivation, risk assumption/aversion, and attitudes regarding control and delegation. Several psychological characteristics have been suggested as being good predictors of entrepreneurial behaviour: (i) the need for selfachievement (e.g. McClelland, 1961); (ii) creativity and initiative (e.g. Hull et al. 1980); (iii) the propensity for risktaking (e.g. Hirsrich\& Peters, 1995); (iv) self-confidence and the "locus of control" (e.g. Brockhaus 1987); (v) desire for independence and autonomy (e.g. Collins \& Moore, 1964; Hornaday\&Aboud, 1971); (vi) motivation, energy and commitment; and (vii) persistence. To these attributes Gorman (1997) adds a variety of values and attitudes, as well as personal objectives. Robinson et al. (1991) stress selfesteem and innovation behaviour as being more relevant than the need for McLeland's classic self-achievement. Davidsson (1989) produced some evidence of a relationship between the need for achievement and individual entrepreneurial behaviour. In several studies, high self-confidence has been identified as a typical trait of entrepreneurs.

Finally, several authors (e.g., Naffzigeret al., 1994), have stressed the importance of contextual factors, arguing that the decision to adopt an entrepreneurial lifestyle is based on something more than merely personal characteristics and psychological traits. From this perspective, analysts need to gain a better understanding of the interaction between $a$ potential entrepreneur's social background and his/her subjective perceptions of the contextual factors in which the decision to become an entrepreneur is taken, and in which patterns of entrepreneurial behaviour are concretely developed and put into practice. 


\section{RESEARCH METHODOLOGY}

We designed a questionnaire, pre-tested and applied during the academic year 2017-2018. A sample was obtained from a population of students who at the time were attending a first degree (undergraduate) course at the University of Can ThoUniveristy. They were directly approached by the interviewers, who visited classrooms throughout the Campus 2. The sample covered a total of 450 students, distributed over 9 courses. The survey was conducted using a selfadministered questionnaire.

The questionnaire contained 20 questions, which included specific demographic descriptors (such as gender, age, student status, and region of origin), as well as data on previous professional experience, academic performance, and the individual's social context. Students were presented with statements designed to measure the extent of their fears with regard to the possible creation of a business venture, provide on assessment of the key difficulties and obstacles they expected to encounter, and to identify factors associated with success in such an initiative. Respondents' attitudes were evaluated using a 5-point Likert scale. Entrepreneurial potential was directly assessed by asking students to indicate the intensity of their current general interest in creating their own business on graduation, and the extent to which they had taken steps to concretise the intention to establish their own firm.

\section{RESEARCH FINDINGS}

The major aim of this study was to assess which are the main determinants of student's entrepreneurial propensity. The nature of the data collected with regard to the dependent variable [Do you intend to create your own business? (1) Yes; (0) No] dictated the choice of the estimation model. Conventional estimation techniques (e.g. multiple regression analysis), in the context of $\alpha$ discrete dependent variable, are not a valid option. First of all, the assumptions needed for hypothesis testing in conventional regression analysis are necessarily violated - it is unreasonable to assume, for instance, that the distribution of errors is normal. Secondly, in multiple regression analysis, predicted values cannot be interpreted as probabilities - they are not constrained to fall in the interval between 0 and 1 (Hosmer \&Lemeshow, 2000).

The logistic coefficient can be interpreted as the change in the log odds associated with a one-unit change in the independent variable. Then, eraised to the power iis the factor by which the odds change when the ithindependent variable increases by one unit. If iis positive, this factor will be greater than 1, which means that the odds are increased; if iis negative, the factor will be less than one, which means that the odds are decreased. When iis 0 , the factor equals 1 , which leaves the odds unchanged. In the case where the estimate of 1 emerges as positive and significant for the conventional levels of statistical significance (that is, $1 \%, 5 \%$ or $10 \%$ ), this means that, on average, all other factors being held constant, female students would have a higher (log) odds of entrepreneurial potential. The estimates of the sare given in Table 1 below.

Table 1 Determinants of students' entrepreneurial trend

\begin{tabular}{|l|l|}
\hline & Estimates (s) \\
\hline Individual characteristics & $-0,539^{\star *}$ \\
(1)Gender (Fem=1) & 0,060 \\
(2)Age & 0,513 \\
(3)Student status (Normal=1) & \\
\hline Psychological characteristics & 0,089 \\
(4)Creativity & $-0,137$ \\
(5)Leadership & $0,303^{* *}$ \\
(6)Risk acceptance/aversion & $-0,017$ \\
(7)Capacity for self-assessment & \\
\hline
\end{tabular}

Contextual factors

(8)Factors related to profession/employment of choice

(9)Extent of entrepreneurship training/

information

(10)Academic training (in general) Constant

Goodness of fit statistics (correct \%)

Hosmer and Lameshow test (p-value)

74,6

$4,142(0,720)$

* Significant at $1 \%$; ** significant at $5 \%$.

Method: Forward Stepwise (Likelihood Ratio)

In this model females demonstrate a much lower trend for entrepreneurship. This ties in with other studies that have indicated that entrepreneurship behaviour is found more commonly in males. Psychologically related factors, namely risk propensity, leadership behaviour, creativity focus and capacity for self-assessment, emerge as critical for explaining students' entrepreneurial intent in the factorial analyse. The main differences between potential entrepreneurs and other students are observed in risk bearing. In this competence the scores of potential entrepreneurs are much higher than those of the remaining students.

\section{V.CONCLUSION}

In summary, the entrepreneurial intentions of undergraduates in Can Tho University are examined along with their related factors. Although a reasonable amount of students in Can Tho University would like to run their own businesses, their intentions are hindered by inadequate preparation, i.e. they recognize that both their practical business knowledge and entrepreneurial preparation are insufficient. Furthermore, one demographic factor (gender), one psychological trait (risk) and two contextual factors (students' declared profession of choice, and academic training) were found to significantly affect students' interest in and motivation for starting their own business.

The pronounced negative influence of students' chosen professions may well be predominantly a question of context and culture: many students arrive at university with clearly established (though not necessarily realistic) ambitions with regard to the profession they wish to follow. This suggests that slowly-changing cultural attitudes, as well as slowlyemerging improvements in the relevance of university training, still influence student decisions regarding selfemployment and entrepreneurship.

The acquisition of specifically entrepreneurship-related training and associated information appears to have no significant bearing on student entrepreneurial trend: this result is probably due to the fact that entrepreneurship modules have only recently been established in Can Tho University programs.

\section{REFERENCES}

1. Brice, J. (2004). The Role of Personality Dimensions on the Formation of Entrepreneurial Intentions. USASBESmallBusiness AdvancentNationalCenter, University of CentralArkansas, USA.

2. Brockhaus, R.H. (1987). Entrepreneurial folklore. Journal of Small Business Management, 25(3) : 1-6.

3. Franke, N. \&Lüthje, C. (2004). Entrepreneurial Intentions of Business Students: A Benchmarking Study. International Journal of Innovation and Technology Management, 1(3): 269-288.

4. Lena, L. \& Wong, P. K. (2003). Attitude towards entrepreneurship education and new venture creation. Journal of Enterprising Culture, 11 (4): 339-357.

5. Martínez, D.; Mora, J-G \& Vila, L. (2007). Entrepreneurs, the Self-employed and Employees amongst Young European Higher Education Graduates. European Journal of Education, 42(1).

6. Rodrigues, R.G.; Raposo, M.; Ferreira, J. \&Paço, A. (2008). Entrepreneurship Education and Business Creation Propensity: Testing a structural model. Int. J. Entrepreneurship and Small Business, 9(1): xx-xx (forthcoming paper).

7. Scott, M.G., \&Twomey, D.F. (1988). The long-term supply of entrepreneurs: students' career aspirations in relation to entrepreneurship. Journal of Small Business Management: 5-13. 